\title{
Experimental research of variable rotation speed ICE-based electric power station
}

\author{
Andrey Dar'enkov \\ Nizhny Novgorod State Technical University n.a. R.E. Alekseev, Institute of Electric Power Engineering, 603950 Nizhny Novgorod, Russia
}

\begin{abstract}
Developing variable rotation speed ICE-based stand-alone electric power stations which can supply distant regions and autonomous objects with electricity are of scientific interest due to the insufficient study. The relevance of developing such electric power stations is determined by their usage is to provide a significant fuel saving as well as increase ICE motor service life. The article describes the electric station of autonomous objects with improved fuel economy. The article describes multivariate characteristic. Multivariate characteristic shows the optimal frequency of rotation of the internal combustion engine. At this rotational speed there is the greatest fuel economy.
\end{abstract}

\section{Introduction}

A major part of the Russian Federation territory is not connected to the central energy power supply system. Such territories include Russian Far East, North, Siberia larger territories and other regions. In these territories are living 10 million people. The main electric power sources of these are electric power stations based on the system "internal combustion engine (ICE) - generator" (E-G) [1]. The existing diesel generators operate at a constant (nominal) rotational speed at different loads. Operation of ICE at a constant rotational speed at variable load is characterized by a non-optimal fuel consumption. This reduces efficiency E-G power station. The article describes the electric station of autonomous objects with improved fuel economy. Improved efficiency is achieved by setting the optimal ICE rotational speed for each value of load power. This optimal speed corresponds to the lowest specific fuel consumption.

\section{E-G power station}

E-G electric power stations, having high reliability, sufficient motor capacity and long period of service is indispensable as stand-alone of main and back-up energy power supply sources. However, the fuel necessary for E$\mathrm{G}$ functioning is transported form distant regions by sea, automobile means and occasionally even by helicopters, which significantly increases its cost. Besides the fuel transportation to distant regions often depends on weather conditions, the season thus it becomes not ever possible. To provide the above regions with electric energy there are used over 50000 of E-G having in total 17 million $\mathrm{kW}$ with electric energy generation of over 50 billion $\mathrm{kWh}$ a year. These power stations fuel consumption is about 6 million tons of oil equivalents [1].
E-G electric power stations are also widely used as back-up energy supply sources on the territory of Russia having a single energy system. E-G power stations are as a rule both the main and back-up energy sources on stand-alone objects, such as merchant and combat vessels, locomotives, automobile transportation etc.

Thus a considerable part of electricity is produced by electric power stations stand-alone E-G. One of the most important tasks of modern Russia is resource-saving, in particular efficient fuel resources utilization. However the overwhelming majority of the existing E-G function at the constant (nominal) shaft speed rotation frequency within the whole range of the load power change. In such E-G, the AC stator synchronous generator (SG) frequency stabilization is provided by the ICE shaft speed stabilization whereas SG stator voltage amplitude stabilization is carried out by the current change in the exciting coil [2]. At this stand-alone E-G function as a rule in the fractional modes their load being within the range of 30 up to $70 \%$ of the nominal one. It is common knowledge that ICE at a constant rotation rate but at an alternating load generally functions with non-optimum fuel consumption (with non-optimum efficiency coefficient) $[2,3]$. To provide the optimal (from the point of view of the fuel consumption) ICE operating mode, it is necessary to change its rotation frequency depending on the load power $[3,4]$.

To choose the economical ICE operating mode, functioning at the changing load, it is practical to use its multivariate characteristic. Fig. 1 shows a typical multivariate ICE characteristic on which by the dashdotted line is shown the effective pressure $p_{\mathrm{e}}$ and the effective power $N_{\mathrm{e}}$ dependency on the frequency of ICE shaft rotation $n$ at the minimal fuel consumption rate $g_{\mathrm{e}}$. 


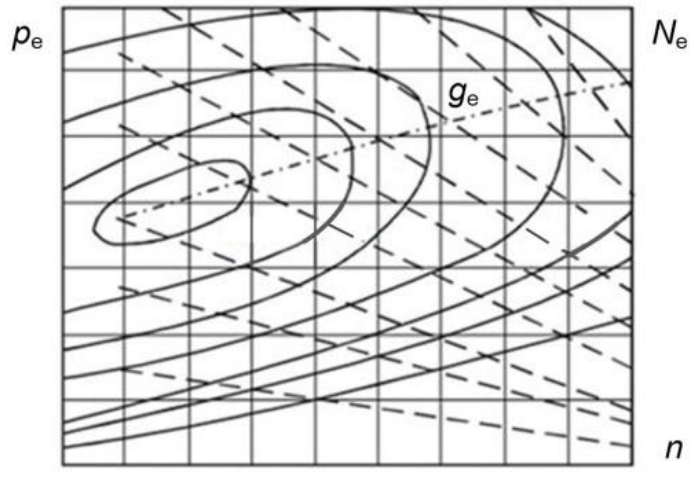

Figure 1. Multivariate characteristic of ICE.

As shown in Fig. 1, at the changing SG load, being rotated by ICE, the electric current is produced, its voltage and frequency being changed, as a rule, lower than nominal values. This requires an innovative approach to building the E-G system able to supply the voltage and frequency output SG frequency stabilization.

The designs of variable speed E-G systems frequency voltage are the prospective ones. The resources to develop these lie within the resource and energy saving, being currently the acute ones. In Russia the following problems are dealt with by S.Petersburg (JSC Zvezda), Moscow (Ltd. NTC Malaya Energetica), Kovrov of Vladimirskaya oblast' (JSC Signa), Tomsk (Tomsk Polytechnic University), in Nizhny Novgorod (Nizhny Novgorod State Technical University after R.E. Alexeev) etc. [4-12].

The existing E-G systems of the variable rotation speed are designed according to the scheme as shown in Fig.2. [5-7,11]. In such systems (see Fig. 2) the voltage frequency at the outputs 6 are stabilized at a set level through the frequency converter (FC) 5 , comprising the rectifier 3 and voltage invertor 4 . The stabilization of SG 2 stator voltage amplitude, connected to the ICE 1shaft, is carried out by the impact of control system 7 on the excitation coil rate SG 2, being such systems deficiency. From the point of view of such system fuel efficiency at the change of load power, the ICE shaft speed is to be calculated within a wide range, the minimal shaft speed being several times different from the nominal one. Thus SG voltage amplitude might change within the wide range, its minimal value being several times lower than the nominal one. At this the SG stator voltage stabilization method, based on the impact of the excitation coil current will not provide the fact of its being supported on its nominal value.

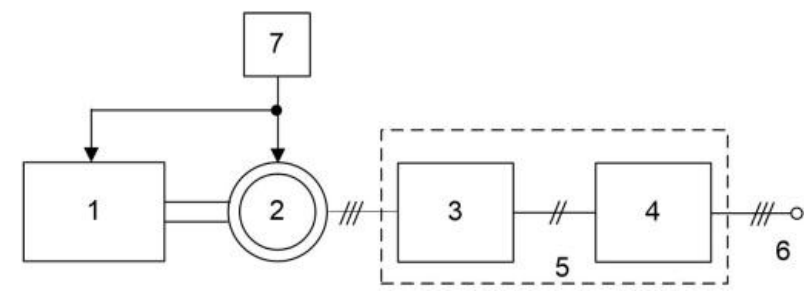

Figure 2. E-G flowchart of variable speed (1 - ICE; 2 - SG; 3 rectifier; 4 - voltage invertor; 5 - FC; 6 - outputs; 7 - control system).
Of interest are also some foreign E-G producers manufacturing invertor power stations, such as SDMO, Honda, Fubag, Hyundai, Kypor etc. These provide lower fuel consumption due to the ICE switch function into the economy saving mode. Invertor power station flowchart is shown in Fig. 3 [9]. Its operation principle is the following: ICE rotates the multipolar generator, its rotor being a permanent magnet. AC three-phase voltage of stator is rectified and DC voltage is converted by an inverter into a sinusoidal voltage with a stable frequency and amplitude.

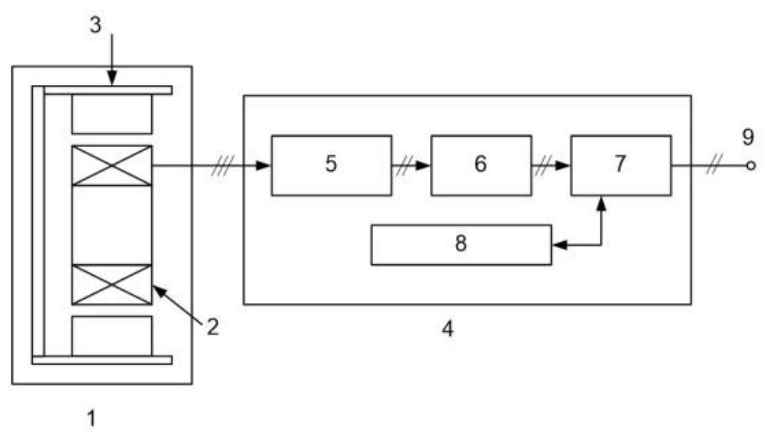

Figure 3. Invertor electric power station flowchart (1 multipolar generator (in section); 2 - generator stator; 3 generator rotor; 4 - DC; 5 - rectifier; 6 - filter; 7 - invertor; 8 microprocessor control system; 9 - outputs).

In this case the economy mode means the ICE transfer to a lower rotating speed at also lowering the load beyond the set limit (about beyond $50 \%$ of the nominal value). An invertor power station is equipped by a special throttle regulating the ICE rotating frequency depending on the load power, which allows reducing the fuel consumption rate by $20 \%$ (see Fig. 4). The parameters stability of the electric power station voltage output is provided by the invertor unit. Voltage amplitude fluctuations are not over $0.5 \%$ [9].

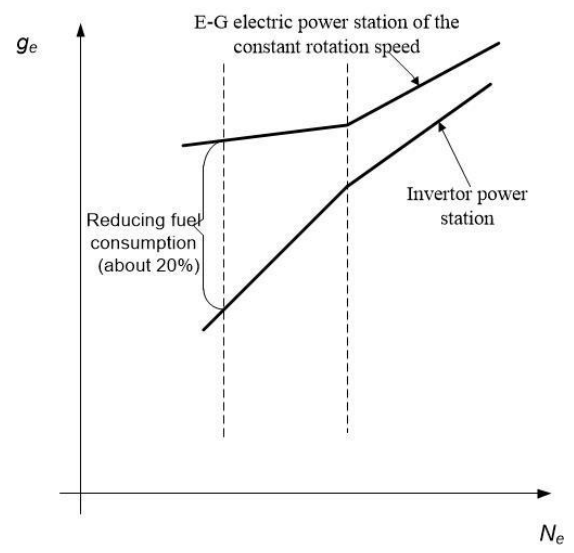

Figure 4. The fuel consumption dependence on the load power of the invertor electric power station and E-G electric power station of the constant rotation speed.

Develop E-G electric power stations of variable speed of rotation is possible ac-cording to the scheme given in Fig. 5 [13-15]. The mechanism functions as follows. The intellectual servomotor of fuel supply control shown by unit 7 receives a signal from the load power evaluator 15 , 
connected to the outputs of voltage sensors 14 and current sensor 4 , measuring the voltage and current at the FC 3 outlet respectively. Depending on the load power value, unit 8 setting the economy mode (SEM) forms a signal, proportionate to the optimal ICE 1 shaft speed. This signal comes to the electric drive 9 inlet of the control rack displacement, supporting the ICE 1 frequency rate at a level set by SEM (unit 8).

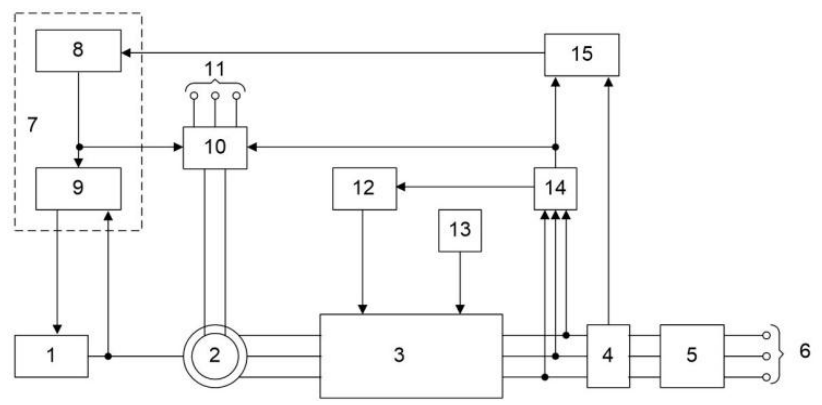

Figure 5. System flowchart of E-G variable rotation speed (1 ICE; 2 - SG; 3 - FC; 4 - current sensor; 5 - step-up transformer; 6 - outputs; 7 - the intellectual servomotor of fuel supply control; 8 - SEM; 9 - electric drive of the control rack displacement; 10 -SG excitation unit; 11 - outlets of SG excitation unit connecting points; 12 - voltage stabilization unit; 13 - output voltage frequency setter; 14 - voltage sensor; 15 load power evaluator).

The AC amplitude stabilization at the outputs 6 at the nominal SG 2 value level is performed by a FC 3 and the step-up transformer 5. SG 10 excitation unit of SG 2 forms current in excitation coil SG 2 at the signal from SEM 8 unit and voltage sensor 14 . The output voltage frequency at outputs 6 with the change of ICE 1 shaft speed rotation frequency is guaranteed the same with the help of FC 3 at the level deter-mined by output voltage frequency setter 13 .

The elementary variant of SEM algorithm might comprise the ICE multivariate characteristic. However multivariate characteristic for each ICE is individual (characteristics of two ICE of the same type and power differ), and ICE manufacturers usually don't provide such characteristics. It is impossible to calculate multivariate characteristic. It is possible to obtain only through the experimental procedure. Besides an ICE multivariate characteristic will vary depending on the outer (pressure, temperature, humidity) and inner (ICE amortization, make and fuel quality) of ICE functioning. So an SEM unit should at the absence of multivariate characteristic automatically calculate the optimal frequency value for the current load power value at a given time with the changing outer and inner ICE functioning conditions. Thus, SEM should be a self-taught system.

SEM flowchart is shown in Fig 6. SEM consists of four basic elements: main controller (MC), content addressable memory (CAM), teaching control (TC) and non-volatile memory (NVM), connected together by a common data bus, which provides a two-way traffic and further system expansion in case of controlling several EG [16-20].

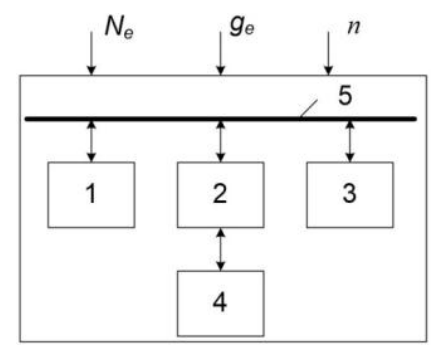

Figure 6. SEM flowchart (1 - MC; 2 - TC; 3 - NVM; 4 - data memory; 5 - data bus).

NVM of SEM is a neural network, which performs the task of table function approximation $n=f\left(N_{e}\right)$, supplemented by the interpolation (extrapolation) procedure. The backpropagation is used for neural network training [16-19].

An E-G experimental research of a variable speed of rotation of the ICE-based electric power station with nominal voltage of $60 \mathrm{~kW}$ has been carried out. The main goal of the research was to determine ICE optimal modes at its speed of rotation fluctuations from 1200 up to 4000 $\mathrm{min}^{-1}$ within the full range of possible load power.

\section{ICE multivariate characteristic}

As a result there have been obtained the sets of experimental motor characteristics comprising the following:

- ICE load-voltage characteristics set for seven speed modes: 1200, 1500, 1600, 2000, 2500, 3200, 3800 min-1;

- ICE outer speed characteristics;

- ICE idling characteristic.

The experimental results give the following:

- multivariate characteristics of fuel-consumption rate within "rotation frequency $n$ - mean effective value $p_{e}$ ";

- multivariate characteristics of fuel combustion heatavailability ratio within "rotation frequency $n-$ net torque $M_{e}^{\prime \prime}$.

ICE multivariate characteristic (Fig.7), being a part of the researched electric power station, has been obtained through processing the above experimental characteristics set. The optimal ICE rotation frequency dependence on the load power from the point of view of fuel consumption is shown in Fig. 7 by the red dotted line.

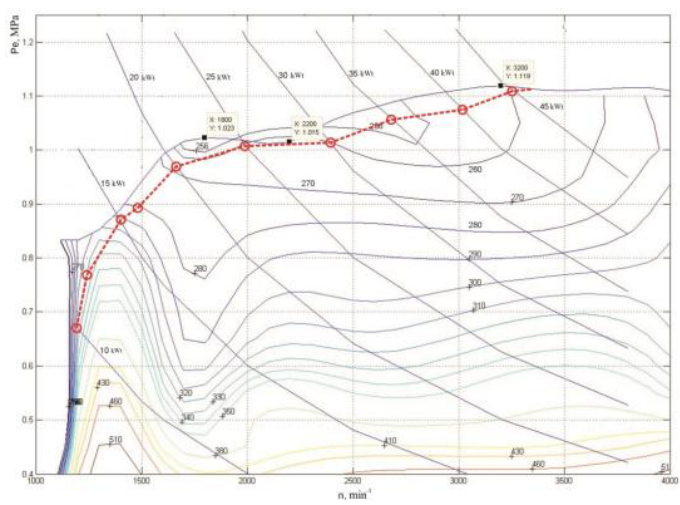

Figure 7. ICE multivariate characteristic with power of $60 \mathrm{~kW}$. 
According to the results of the research the following conclusions have been made:

1. Experimental areas of consumption rate $g_{e}$ show the necessity of wide frequency fluctuations of the researched E-G electric power station within the range of $1500-3500 \mathrm{~min}^{-1}$ to optimize the fuel consumption while changing the electric power station capacity.

2. In the case of optimal choice of ICE rotation frequency variation it is possible to significantly improve the E-G electric power station efficiency.

As an example, for the researched electric power station Fig. 1 shows the following:

- dependence of fuel consumption rate $g_{e}^{3000}$ on power at the ICE constant rotation frequency $3000 \mathrm{~min}^{-1}$;

- dependence of fuel consumption rate $g_{e}{ }^{V A R}$ on power $N_{e}$ at the ICE variable rotation frequency.

The lines corresponding to 2-fold power control reduction are shown in table 1 . Herewith, the fuel saving at controlling the ICE rotation frequency is $26 \%$ as compared to the experiment in which the ICE rotation frequency was leveled off at $3000 \mathrm{~min}^{-1}$.

Research shows that the ICE rotation frequency control, being a part of E-G electric power station, at load power change allows reducing the fuel consumption rate to $20-30 \%$. Consequently the E-G variable frequency system operation significantly economizes the use of expensive fuel resources. Simultaneous change of rotation frequency and load power provides the optimal ICE thermal conditions operation, and thus an increase of its motor service life.

\begin{tabular}{|c|c|c|c|c|}
\hline $\mathbf{N}_{\mathrm{e}}, \mathbf{k W}$ & $\begin{array}{c}\mathbf{G}_{\mathbf{E}}{ }^{\mathbf{3 0 0 0}}, \\
\mathbf{G} / \mathbf{K W H}\end{array}$ & $\begin{array}{c}\mathbf{g}_{\mathbf{e}}^{\text {VAR }} \\
\mathbf{g} / \mathbf{k W h}\end{array}$ & $\begin{array}{c}\mathbf{g}_{\mathbf{e}}{ }^{\text {VAR }} \\
\mathbf{g}_{\mathbf{e}} \mathbf{3 0 0 0}\end{array}$ & $\begin{array}{c}\text { Fuel } \\
\text { saving, } \%\end{array}$ \\
\hline 45 & 260 & 260 & 1 & 0 \\
\hline 40 & 258 & 258 & 1 & 0 \\
\hline 35 & 264 & 250 & 0.95 & 5 \\
\hline 30 & 288 & 260 & 0.90 & 10 \\
\hline 25 & 315 & 262 & 0.83 & 17 \\
\hline 20 & 360 & 268 & 0.74 & 26 \\
\hline 15 & 460 & 280 & 0.61 & 39 \\
\hline
\end{tabular}

\section{Conclusion}

Experimental research of a variable speed of rotation of the ICE-based electric power station with nominal voltage of $60 \mathrm{~kW}$ has been carried out in accordance with the developed and approved program and test pattern. The algorithm of the SEM variable frequency ICE-based electric power station operation has been developed on the basis of neural networks apparatus. The back propagation has been used for neural network training.

There have been obtained multivariate fuel consumption rate areas, as well as fuel economy estimate for the variable rotation frequency $60 \mathrm{~kW}$ ICE-based power stations.

Using variable frequency ICE-based electric power stations let's get the reduction of fuel rate consumption of up to $30 \%$. The simultaneous change of rotation frequency and load power provides the optimal ICE thermal conditions operation, and thus increases its motor service life.

\section{Acknowledgment}

The research was performed with the support of the State Research Program (project № 8.2668.2014/K) on department «Electrical equipment, electric drive and automatics» of Nizhny Novgorod State Technical University n.a. R.E. Alekseev.

\section{References}

1. O.V. Fedorov, A.B. Dar'enkov. Energy saving politics (Knorus, Moscow, 2015)

2. V.A. Michaylov. Automated electric power systems of vessels (Sudostroenie, Leningrad , 1977)

3. A.S.Orlin, M.G. Kruglov. Internal Combustion Engines: Theory of reciprocating and compound engines (Mashinostroenie, Moscow, 1983)

4. O.S. Khvatov, A.B. Dar'enkov, I.M. Tarasov. Vestnik IGEU. Diesel-generator Power Plant with Shaft Frequency Rotation, 2, 53 (2010)

5. O.A. Aleshkov. Primary diesel motor fuel consumption economy enhancement as a part of multifunctional energotechnological complex by optimizing the speed mode, dissertation work, Barnaul, (2009)

6. N.M. Parnikov. Decentralized power supply energy efficiency complexes enhancement as exemplified in Saha Republic (Yakutia), dissertation work, Tomsk (2009)

7. M.A.Surkov. Wind-diesel electrotechnical complexes energy performance optimization, dissertation work, Tomsk (2011)

8. I.A.Tarpanov. Stand-alone generator complexes of variable rotation frequency, dissertation work, $\mathrm{N}$. Novgorod (2012)

9. I.S. Polakov. Diesel driven generator, dissertation work, N. Novgorod (2013)

10. I.S. Samoyavchev. Stand-alone objects electric power station on variable rotation frequency-based diesel driven generator, dissertation work, N. Novgorod (2014)

11. A.E. Zagorsky, U.G. Shakaryan. Independent fix frequency power supply source (variants). RF patent 34817, 10 Oct 2003

12. Honda Information, http://www.honda.co.ru/powerproducts/documents

13. A.B. Dar'enkov, O.S. Khvatov. AC stand-alone electric power station, RF patent 2412513, 10 Dec 2011

14. A.B. Dar'enkov, O.S. Khvatov. AC stand-alone electric power station, RF patent 137701, 05 Feb 2014

15. A.B. Daryenkov, O.S. Khvatov. News of the Tula state university. Technical sciences. Intelligent controls of highly effective the diesel-generator installation of variable frequency of rotation, 3, 126 (2010)

16. O.S. Khvatov, A.B. Daryenkov, I.S. Polyakov. Vestnik IGEU. Neural Network Algorithm of Control System of Fuel Supply of Frequency Rotation Diesel Generator Set, 3, 50 (2013) 
17. O.S. Khvatov, A.B. Daryenkov. Promishlennaya energetika. A stand-alone diesel electric power station with a neural network economy mode cof neural network economy mode setting device, 12, 26 (2013)

18. O.S. Khvatov, A.B. Dar'enkov, Russian Electrical Engineering. Power plant based on a variable-speed diesel generator, 85, 145 (2014)
19. A.B. Dar'enkov, V.I. Erofeev. Proceeding of International conference on informatics, networking and intelligent computing. Semiconducting invertor generators with minimal losses, 227 (2015) 